Revista Culturas Jurídicas, Vol. 7, Núm. 16, jan./abr., 2020

\title{
O ACESSO E EXIGIBILIDADE AO DIREITO À MORADIA NA PERSPECTIVA DO CONSTITUCIONALISMO DIRIGENTE ${ }^{1}$
}

\author{
THE ACESS AND EXIGIBILITY TO THE RIGHT TO DWELLING IN THE PERSPECTIVE \\ OF THE DIRECTING CONSTITUTIONALISM
}

Vanessa Aguiar Figueiredo $^{2}$
Marcelo Nunes Apolinário $^{3}$

Resumo: A presente investigação busca discutir o fenômeno da exigibilidade do direito social à moradia. O objetivo é enfrentar e analisar alguns elementos tangentes às questões que envolvem o constitucionalismo dirigente e a problemática que gravita em torno da escassa justiciabilidade do direito à moradia digna e a correlação com a baixa carga de efetividade atribuída às normas programáticas. Primeiramente, abordar-se-á acerca da moradia enquanto direito humano, social e fundamental nos principais aportes jurídicos. Posteriormente, as aspirações da teoria da constituição dirigente, de J.J. Gomes Canotilho, no âmbito do constitucionalismo contemporâneo. Assim, entende-se que o problema que assola a justiciabilidade dos direitos sociais está ligado a própria conjuntura estrutural que deu origem a estes direitos, quando comparados com os direitos civis e políticos, carecendo de instrumentos jurídicos e estratégias próprias, o que inviabiliza a implementação de políticas habitacionais. Utilizou-se a revisão bibliográfica- documental como método investigativo.

Palavras-chave: Exigibilidade; Direito à moradia; Direitos sociais; Constituição dirigente.

Abstract: This investigation seeks to discuss the phenomenon of the enforceability of the social right to housing. The objective is to face and analyze some elements tangent to the questions that involve the dirigent constitutionalism and the problem that gravitates around the scarce justiciability of the right to worthyhousing and the correlation with the low load of

\footnotetext{
${ }^{1}$ Artigo submetido em 20/04/2020 e aprovado para publicação em 11/06/2020.

2 Advogada. Mestre em Direito pela Universidade Federal de Pelotas (UFPel) . Especialista em Direito/ Processo do Trabalho pelo Complexo Damásio de Jesus. Bacharel em Direito pela Universidade Federal de Rio Grande. ORCID: https://orcid.org/0000-0003-2147-7054.

${ }^{3}$ Possui graduação em Direito pela Universidade Católica de Pelotas (2003), Diploma de "Estudios Avanzados" en Derecho penal pela Universidad Autónoma de Madrid (2005), Doutorado em Derechos Fundamentales pela Universidad Autónoma de Madrid (2010), especialista em Direito Civil e Processual Civil, pela Universidade UNIDERP e especialista em Didática e Metodologia do Ensino Superior pela UNIDERP. Professor de Hermenêutica Jurídica, Direito Eleitoral e Teoria da Constituição na Faculdade de Direito da UFPEL. Professor das disciplinas Teoria dos Direitos Fundamentais e Constituição e Estado Social do Programa de Mestrado em Direitos Sociais da Faculdade de Direito da UFPEL. Coordenador do Projeto de Pesquisa Estado, Constituição e Direitos Fundamentais (UFPEL). Coordenador do Grupo de Estudos Constituição, Cidadania e Direitos Fundamentais (UFPEL). Pós doutorando em Direito pela Universidad Autónoma de Madrid. Áreas de pesquisa: Direito Constitucional, Teoria do Direito, Direito Eleitoral, Política Criminal, Direitos Fundamentais e Direitos Humanos. ORCID: https://orcid.org/0000-0001-7140-4625.
} 
effectiveness attributed to the programmatic norms. Primeirelly, it will address housing as a human, social and fundamental right in major legal contributions. Subsequently, the aspirations of the theory of the dirigente constitution, from J.J. Gomes Canotilho, within the scope of contemporary constitutionalism. Thus, it is understood that the problem that plagues the justiciability of social rights is linked to the very structural situation that gave rise to these rights, when compared to civil and political rights, lacking legal instruments and strategies, which makes implementation impossible housing policies. The bibliographical review was used as an investigative method.

Key words: Demandability; Right to housing; social rights ; Dirigente Constitution.

\section{Introdução}

Reconhecido como um direito humano, a moradia é um dos corolários da dignidade humana. Desde os primórdios, a morada tornou-se uma das principais preocupações dos seres humanos, desde que deixaram de ser nômades até o momento que passaram a serem sedentários e terem a necessidade então, de ter um local para abrigo e proteção.

$\mathrm{O}$ direito à moradia passou a incorporar os principais documentos jurídicos tanto em nível nacional como internacional, tornando-se uma obrigação estatal fornecer subsídios formais e materiais para o acesso a este direito.

No constitucionalismo contemporâneo, a tutela jurídica do direito à moradia foi proporcionada pelo avanço protetivo em relação aos direitos sociais, principalmente à luz da teoria da Constituição dirigente proposta por José Joaquim Gomes Canotilho. Porém, há uma forte resistência à implementação destes preceitos enquanto direitos subjetivos e a possibilidade de serem exigíveis judicialmente.

No Brasil, a moradia também é um problema social e que ainda demanda soluções. Ademais, com o crescimento desenfreado dos centros urbanos, grande parte da população não consegue ter um local decente para se abrigar, outros sequer possuem. Também a falta de políticas públicas direcionadas ao real e efetivo problema da habitação não é uma exclusividade brasileira. Uma gama considerável de países periféricos, dentre os quais, grande parcela que se encontra ao nosso entorno, convive com a falta de estratégias governamentais capazes de sanar ou minimizar esse problema que compreende um direito humano fundamental.

$\mathrm{O}$ presente artigo visa então, averiguar o acesso à moradia no Brasil, principalmente naquilo que trata da questão de sua exigibilidade, enquanto pretensão demandável judicialmente no contexto das constituições dirigentes e do pensamento do 
constitucionalismo contemporâneo. Em razão disso, o problema que a pesquisa visa responder é se o acesso ao direito à moradia está condicionado a escassa exigibilidade deste direito por ser considerado norma programática.

Para tanto, num primeiro momento estudar-se-á as considerações iniciais acerca do acesso à moradia enquanto direito fundamental e social e sua positivação nos documentos jurídicos tanto de aporte nacional como internacional, materializando um aparato jurídico dos principais documentos de proteção à habitação.

A partir disso, analisar-se-á o chamado constitucionalismo dirigente, fruto da teoria de José Joaquim Gomes Canotilho, que preconiza nos textos constitucionais o caráter compromissório e traça objetivos a serem almejados pelo Estado, na ótica dos direitos sociais e o tratamento enquanto normas programáticas.

$\mathrm{Na}$ terceira e última etapa da investigação, o objeto de estudo versará sobre os obstáculos que envolvem a exigibilidade judicial da moradia, enquanto direito subjetivo, principalmente a partir de seu viés prestacional (positivo) na Constituição brasileira. Com enfoque nas questões sobre os obstáculos à justiciabilidade dos direitos sociais, principalmente em relação a conduta do poder estatal em relação à concretização do direito à moradia.

Este trabalho utilizou a revisão bibliográfica- documental de caráter qualitativo como método investigativo.

\section{Acesso à moradia enquanto direito humano, fundamental e social}

A moradia ${ }^{4}$ foi reconhecida como direito humano, com a Declaração Universal dos Direitos Humanos das Nações Unidas no ano de 1948, em seus artigos 22 a 27. No art. 25, consta que toda pessoa tem direito a um nível de vida suficiente para assegurar a sua saúde, o seu bem-estar e o de sua família, especialmente para a alimentação, o vestuário, a moradia, a assistência médica e para os serviços sociais necessários, e o direito à segurança em caso de desemprego, doença, invalidez, viuvez, velhice ou outros casos de perda dos meios de subsistência, em circunstâncias fora do seu controle.

\footnotetext{
4 “Art. 25, 1 ${ }^{\circ}$. Toda pessoa tem direito a um padrão de vida capaz de assegurar a si e a sua família saúde e bemestar, inclusive alimentação, vestuário, habitação, cuidados médicos e os serviços sociais indispensáveis, e direito à segurança em caso de desemprego, doença, invalidez, viuvez, velhice ou outros casos de perda dos meios de subsistência fora de seu controle."
} 
Nesta seara, o direito de moradia começou a aparecer em vários documentos internacionais, principalmente em Tratados, em especial no Pacto Internacional de Direitos Econômicos, Sociais e Culturais (PIDESC), em que estabelece no art. $2^{\circ}$, que cada EstadoParte do presente Pacto compromete-se a adotar medidas, tanto por espaço próprio como pela assistência e cooperação internacionais, principalmente nos planos econômicos e técnicos, até o máximo de seus recursos disponíveis, que visem a assegurar, progressivamente, por todos os meios apropriados, o pleno exercício dos direitos reconhecidos no presente Pacto, incluindo, em particular, a adoção de medidas legislativas.

$\mathrm{Na}$ mesma direção, o art. 11 , item $1^{\circ}$, do Pacto ressalta que Os Estados-partes no presente Pacto reconhecem o direito de toda pessoa a um nível de vida adequado para si próprio e para sua família, inclusive à alimentação, vestimenta e moradia adequadas, assim como uma melhoria continua de suas condições de vida. Os Estados-partes tomarão medidas apropriadas para assegurar a consecução desse direito, reconhecendo, neste sentido, a importância essencial da cooperação internacional fundada no livre convencimento.

Portanto, observa-se que o objetivo desse Pacto foi permitir a adoção de uma linguagem de direitos que implicasse obrigações no plano internacional. Os direitos concebidos neste pacto, apresentam realização progressiva e os Estados se obrigam a adotar medidas, até o máximo dos recursos disponíveis, a fim de alcançarem progressivamente a plena concretização desses direitos.

Além do Pacto Internacional dos Direitos Econômicos, Sociais e Culturais, no âmbito do sistema interamericano de salvaguarda aos Direitos Humanos (OEA), vinculam-se diretamente com o direito à moradia o art. 11 da Convenção Americana de Direitos Humanos e o art. 34, K, da Carta da Organização dos Estados Americanos.

Com a sua expansão normativa, a moradia abrangeu o conceito de "moradia adequada". A previsão estabeleceu que este direito consiste além de um simples teto, envolvendo também, infraestrutura, saneamento básico, saúde e lazer.

Após a Declaração de Direitos, inúmeros instrumentos internacionais visaram proteger o direito à moradia. A Declaração sobre Assentamentos Humanos de Vancouver (1976) e a Agenda 21 sobre Meio Ambiente e Desenvolvimento (1992) são exemplos da tratativa deste direito no plano internacional.

Sobre o tema de implementação do direito à moradia no campo formal, Sarlet destaca, entre outros instrumentos internacionais: 
[...] a Convenção Internacional sobre a eliminação de todas as formas de discriminação racial (1969), cujo art. $5^{\circ}$ assegura, sem discriminação por motivos de raça, cor, nacionalidade ou origem étnica, entre outros direitos, o direito à moradia. Em termos semelhantes, também as Convenções Internacionais sobre a eliminação de todas as formas de discriminação contra a mulher (1979), a Convenção Internacional sobre os direitos das crianças (1989), bem como a Convenção sobre a proteção dos direitos dos trabalhadores migrantes (1990), contém dispositivos reconhecendo um direito à moradia, com alguma variação no que diz com dimensões específicas deste direito [...](SARLET, 2010, p.17)

No direito constitucional contemporâneo não podia ser diferente, o direito de ter um domicílio começou a aparecer nos textos constitucionais do $2^{\circ}$ pós-guerra. No Brasil, mesmo que de forma tímida, desde a Constituição de 1824 os direitos sociais estão presentes, incluindo-se a moradia, seguindo o paradigma das Declarações de Direitos da Revolução Francesa de 1789. Todavia, somente com a Constituição Federal de 1988 que o direito de moradia se tornou direito fundamental da pessoa humana (LOPES, 2014).

A Constituição Federal de 1988 traz a moradia expressa pela primeira vez no direito constitucional pátrio. Preconiza o art. 23, inciso IX, da Constituição Federal de 1988: "é competência comum da União, dos Estados, do Distrito Federal e dos Municípios promover programas de construção de moradias e a melhoria das condições habitacionais e de saneamento básico".

Com o advento da Emenda Constitucional $n^{\circ} 26$, de 2000, a moradia foi incorporada no rol dos direitos sociais (art. $6^{\circ}$, caput, da $\mathrm{CF} / 88$ ) de forma tardia. A Constituição resguardou o direito de moradia pelo Estado de forma positiva, no qual a função estatal é estabelecer políticas públicas que visem tutelar este direito. Em razão disso, a Carta Magna brasileira também frisou que a atribuição de promover programas que visem a construção e melhorias nas moradias é de competência comum ${ }^{5}$, como já mencionado, entre os entes federados.

Pelo texto constitucional vigente, o termo moradia deve vir sempre acompanhado do conceito de dignidade humana. Não basta ter somente um teto, um lar para habitar, é muito mais do que isso. A moradia envolve assegurar condições mínimas que respeite a dignidade humana, devendo assegurar as necessidades naturais e sociais de seus habitantes. Assim, é o direito de moradia bem mais que a simples propriedade propriamente dita, é um espaço e local que deve ser garantido o bem-estar, intimidade, saúde e lazer. Nesse diapasão, a

\footnotetext{
5 “É competência comum da União, dos Estados, do Distrito Federal e dos Municípios promover programas de construção de moradias e a melhoria das condições habitacionais e de saneamento básico."
} 
moradia passa a ser um valor que envolve a garantia de um abrigo digno e salubre capaz de promover conforto e segurança de seus habitantes. Nesse aspecto, encontra guarida no direito à vida, no direito à saúde, na proteção da família, no direito ao meio ambiente, no acesso à propriedade (AINA, 2004).

Outrossim, a função social da propriedade como garantia individual também foi resguardada na Constituição Federal de 1988, no art. 5º, inciso XXIII, assegurando a propriedade como um munus que está vinculada a desempenhar uma função social.

De plano, é possível notar que o direito de ter um lar é um direito humano por excelência, preconizado em vários documentos internacionais, sua construção jurídica percorreu vários documentos com o intuito de tutelar este direito, porém, malgrado a sua positivação normativa, o acesso à moradia é um dos problemas sociais mais severos que assola a população mais carente e desencadeia uma série de problemas sociais, não só no Brasil este problema está presente, como em vários países com economia emergente. ${ }^{6}$

A partir das considerações preliminares aqui tecidas, se discutirá sobre o constitucionalismo de cunho dirigente na Constituição brasileira e nas constituições de alguns países do entorno, que buscaram, de certa forma, emancipar as sociedades que por longos anos viveram em um período de opressão política e ideológica no regime ditatorial e sua dialética relação com o acesso à moradia, enquanto objetivo a ser perseguido pelos Estados.

\section{As aspirações da teoria da constituição dirigente no contexto do constitucionalismo brasileiro e a sua relação com o direito fundamental à moradia}

No Estado Contemporâneo é inegável o papel dos textos constitucionais principalmente em assegurar os direitos e liberdades dos indivíduos, porém, o debate em torno da Constituição em especial sobre o seu papel na sociedade começou a se intensificar com o segundo pós-guerra.

Travou-se um debate constitucional entre aqueles que consideravam que a Constituição deveria limitar-se a ser um simples instrumento definidor de competências estatais e procedimentais. Há outros, contudo, que creem que o texto constitucional deveria ser mais

\footnotetext{
${ }^{6}$ Não há uma definição exata do que seria considerada economia emergente, porém, podemos dizer que são aqueles países cujas economias partiram de um estágio de estagnação e se encontram em pleno desenvolvimento econômico. São também chamados de "países em desenvolvimento".
} 
que isso: também deveria ter um caráter transformador da sociedade, além de um simples instrumento de governo.

Nesta seara, surge a Teoria da Constituição Dirigente, proposta pelo jurista português Joaquim José Gomes Canotilho em sua tese de doutoramento intitulada Constituição Dirigente e Vinculação do Legislador: contributo para a compreensão das normas constitucionais programáticas, escrita em 1982.

Para Canotilho, a noção de Constituição deveria ser além de estabelecer os princípios materiais estruturantes do Estado, tais como as noções de Estado de Direito (constitucional), de democracia e República para impor tarefas e programas que os poderes públicos devem concretizar. A Constituição deixa de ser um instrumento de governo, definidor de normas e competências para o exercício do poder, insistindo-se como programática (programas e fins do Estado).

A premissa básica sustenta que uma verdadeira Constituição deve conceber-se como estatuto organizativo, como instrumento de governo, capaz de definir competências e regular processos. A Constituição deve transformar-se num plano normativo-material global que determina tarefas e programas estatais (CANOTILHO, 2001).

O jurista português com sua tese da Constituição dirigente, pretendia demonstrar que o legislador não deveria ser tão livre como vinha se mostrando no direito constitucional, por isso o termo "vinculação do legislador" em sua obra. O legislador deveria se vincular às normas constitucionais como os demais poderes constituídos. Tendo em vista esta concepção de Constituição, o autor possui duas preocupações centrais (CANOTILHO, 2001): a primeira é a defesa da não- disponibilidade da Constituição pelo legislador e a segunda trata da questão da discricionariedade legislativa.

A tarefa do dirigismo constitucional é tentar reavivar no direito constitucional contemporâneo a importância da Constituição precípua de se alcançar a justiça social. Para alcançar este fim, a Constituição teve de reaver o seu caráter invasivo principalmente porque se incumbiu de estabelecer diretrizes para às políticas públicas como de organizar o planejamento estatal, conforme discorre Paolo Comanducci:

un proceso al término del cual el derecho es 'inpregnado', 'saturado' o 'embebido' por la Constitución: un derecho constitucionalizado se caracteriza por una Constitución invasiva, que condiciona la legislación, la jurisprudencia, la doctrina y los comportamientos de los actores políticos. (COMANDUCCI, 2002, p. 95) 
Neste aspecto, o próprio Canotilho assenta que toda Constituição visa aliar o jurídico com o político, sobretudo ter um caráter revolucionário de constituir-se como uma ordem material fundamental que define o próprio conteúdo a ser alcançado tanto pelo Estado como pela sociedade em geral (CANOTILHO, 2001).

Em linhas mestras, a teoria da constituição dirigente estabelece que o texto constitucional deve influir em uma projeção quase futurista da realidade, de forma utópica com mudanças orientadas pelo próprio legislador.

As intituladas constituições dirigentes surgiram principalmente na passagem do período autoritário dos regimes militares para a transição democrática de retorno da ordem jurídica voltando a então ligação entre sociedade, Estado e Direito. Países como Brasil, Portugal e Espanha incorporam em seus textos as aspirações dirigentes principalmente no intuito de resguardar no texto constitucional os fins e objetivos do Estado Democrático de Direito.

As novas Constituições dirigentes não pautam-se somente na incumbência da transformação social e política aliada aos seus textos constitucionais, como também, há um plus normativo em busca da promoção dos historicamente excluídos, bem como, um pluralismo jurídico ${ }^{7}$ e a descolonização ${ }^{8}$ constitucional.

O "triunfo tardio" do direito constitucional brasileiro, orientado pelo marco teóricofilosófico do pós-positivismo, é o que possibilita o advento de uma nova hermenêutica constitucional, passando a ser reconhecida a força normativa da Constituição, o que calha, também, na expansão da jurisdição constitucional (BARROSO, 2011).

De forma sintética, verifica-se que o texto constitucional brasileiro de 1988 reconhece um rol extenso de direitos sociais. No entanto, para que os direitos sociais possam efetivamente ser concretizados e usufruídos pelos cidadãos, far-se-á necessário a dependência do desenvolvimento de programas e políticas públicas, que visam tutelar os mais diversos grupos sociais, principalmente àqueles que se encontram em notável grau de vulnerabilidade.

Como ensina Habermas, o Estado social está alicerçado na dialética existente entre a igualdade formal de índole jurídica e as desigualdades reais. A missão do Estado social consiste em assegurar condições de vida sociais, tecnológicas e ecológicas que permitam a

\footnotetext{
7 Trata-se da diversidade de normas que vigem em uma determinada sociedade de forma simultânea em contraposição ao monismo jurídico, que é o monopólio das normas exercidas pelo Estado.

${ }^{8}$ Revela-se como a tendência de tutelar nos textos constitucionais o pluralismo e a diversidade, resgatando e valorizando sociedades mestiças e multiétnicas.
} 
todos os membros de uma determinada comunidade, em condições de igualdade de oportunidade, tirarem proveito dos direitos cívicos equanimemente distribuídos (HABERMAS, 1998).

As novas tendências constitucionais, não obstante, demonstram que estas além de serem cartas políticas que romperam com os períodos autoritários vivenciados por grande parte dos países do entorno, estabelecem ditames jurídicos do modo de agir do Estado, de buscar mecanismos institucionais e financeiros que viabilizam a concretização dos preceitos constitucionais, principalmente os direitos fundamentais de natureza social.

Estando a moradia positivada no ordenamento jurídico brasileiro (arts. $6^{\circ}$, Caput e 23, IX da Constituição Federal) como direito humano fundamental, não pode este direito ser tratado meramente como mercadoria, acessível somente àqueles que possuem condições econômicas de pagar o seu preço de mercado. Daí surge a importância de políticas públicas para universalizar a moradia digna enquanto necessidade essencial de todo ser humano, como bem jurídico extrapatrimonial indispensável ao respeito da dignidade (SERRANO JÚNIOR, 2012).

A efetividade do direito à moradia constitucionalmente garantido em um país marcado pelas desigualdades, como é o Brasil, depende das políticas públicas redistributivas. Por essa razão, se faz importante a construção de estratégias de universalização do direito à moradia digna estarem contempladas nos planos de desenvolvimento econômico e social, no próprio planejamento da atuação estatal, como clama a Constituição do estilo dirigente, contando com a disponibilidade de recursos adequados e estáveis nos orçamentos públicos (SERRANO JÚNIOR, 2012).

Entretanto, apesar do avanço normativo, especialmente no fortalecimento dos direitos fundamentais, do Estado Democrático de Direito e de um direito constitucional que reconhece às diferenças, a incumbência de concretizar determinados direitos sociais ainda permanece. Por isso, a seção seguinte será dedicada a analisar o a exigibilidade do direito social à moradia no âmbito do constitucionalismo dirigente, bem como a carência de políticas públicas habitacionais consistentes em países periféricos como o Brasil.

\section{A busca pela jusfundamentalidade dos direitos sociais e obstáculos para a justiciabilidade do acesso ao direito à moradia no brasil}


Apesar de a Declaração de Direitos do Homem não ter estabelecido diferenças entre direitos sociais com relação aos direitos civis e políticos ou qualquer tipo de hierarquia, os primeiros sofrem com obstáculos denegatórios de sua exigibilidade. A doutrina ainda tenta buscar mecanismos para equiparar os direitos sociais ao mesmo grau de importância que se encontram os direitos civis e políticos.

Primeiramente, há de se compreender ambas categorias de direitos humanos. A primeira categoria abarca os direitos civis e políticos. Os primeiros referem-se às liberdades individuais, como o direito à vida, à liberdade de expressão e a igualdade perante a lei. Por outro lado, os direitos políticos são ligados a cidadania e referem-se à participação do cidadão nos atos do governo de um Estado.

A segunda categoria de direitos humanos institui os direitos econômicos, sociais e culturais. Primeiramente os direitos econômicos seriam aqueles que organizam a vida econômica de um Estado, de forma individual ou de promoção de uma categoria, como o direito de greve. Já os direitos sociais são os direitos tendentes a assegurar uma vida material minimamente digna, exigindo prestação positiva do Estado em favor dos indivíduos que delas necessitem. E por fim, os direitos culturais são entendidos como aqueles relacionados à participação do indivíduo na vida cultural de uma comunidade (SERRANO JÚNIOR, 2012).

De pronto, cabe enfatizar que os direitos humanos compõem uma unidade indivisível e interdependente que deve conjugar ambas as categorias de direitos, sem distinção ou hierarquia. Apesar disso, há uma série de obstáculos que os direitos sociais sofrem se comparado aos direitos civis e políticos, principalmente em relação a exigibilidade judicial:

Em face da indivisibilidade dos direitos humanos, há de ser definitivamente afastada a equivocada noção de que uma classe de direitos (a dos direitos civis e políticos) merece inteiro reconhecimento e respeito, enquanto outra classe (a dos direitos sociais, econômicos e culturais), ao revés, não merece qualquer observância. (PIOVESAN, 1997, p. 151)

É oportuno, antes de mais nada, retornar à história dos principais documentos internacionais que estabeleceram estas categorias de direitos. A Declaração de Direitos é considerado o marco da criação do chamado "Direito Internacional dos Direitos Humanos". Com a sua instauração, surgiu a dúvida de qual seria a melhor maneira de juridicizar tal documento, afim de que tivesse mais efetividade. Em razão disso, a declaração foi juridicizada sob a forma de um tratado internacional de vinculação obrigatória no âmbito do direito internacional. 
Esse processo começou no ano de 1949 e foi concluído em 1966, com a elaboração de dois pactos distintos que abarcavam as categorias de direitos: o Pacto Internacional dos Direitos Civis e Políticos e o Pacto Internacional dos Direitos Econômicos, Sociais e Culturais. A elaboração de dois Pactos, por si só, revela as ambivalências e as resistências dos Estados em conferir igual proteção as categorias de direitos (PIOVESAN, 1997).

A própria justificativa sobre a elaboração de dois pactos distintos já coloca em voga o tratamento que cada categoria recebe. Os argumentos usados foram de que os direitos civis e políticos seriam normas de aplicação imediata enquanto os direitos econômicos, sociais e culturais deveriam ser implementados progressivamente. $\mathrm{O}$ segundo argumento foi o de que havia possibilidade de se estabelecer mecanismos de supervisão para os direitos civis e políticos, o mesmo não poderia acontecer para os direitos sociais e econômicos (CUNHA; SCARPI, 2007).

Neste raciocínio, ainda se discute sobre a jusfundamentalidade dos direitos sociais, quando ao reconhecimento dos direitos sociais como direitos fundamentais e propícios de serem demandados judicialmente. Com isso, parte da doutrina, atribui aos direitos sociais como direitos que aguardam uma prestação positiva do Estado, enquanto os direitos civis e políticos, ao contrário, pretendem uma abstenção do poder estatal.

A diferenciação ainda ocorre em relação a densidade normativa. Os direitos de defesa (direitos civis e políticos) e os direitos de prestação (direitos sociais) são classificados conforme a estrutura jurídico- normativa. Reflete assim, na classificação de aplicabilidade de tais direitos. Os direitos de defesa são comumente classificados como de aplicação imediata, os direitos sociais (de prestação) de aplicação mediata e devidos progressivamente.

Um importante fator que propiciou a proteção judicial dos direitos sociais foi a adoção do Protocolo Facultativo ao Pacto de direitos econômicos, sociais e culturais, que apesar de entrar em vigor somente em 2013, possibilitou a apresentação de queixas perante o Comitê de Direitos Econômicos, Sociais e Culturais quando houver violação de tais direitos:

El Protocolo Facultativo vino a romper esta falta de protección judicial o cuasijudicial de los derechos económicos, sociales y culturales a nivel internacional - de modo que la adopción por parte de la comunidad internacional de un instrumento que acepta que es posible para los titulares de derecho presentar una queja ante un tribunal o un órgano de protección internacional en materia de derechos sociales significa que la comunidad internacional acepta que la justiciabilidad de derechos es conceptualmente posible y ofrece vías para la concreción de su tutela internacional. Esto permite formular el mismo argumento en el plano nacional: la incorporación de derechos sociales en la Constitución implica también el reconocimiento de la 
aplicación de este principio de acceso a la justicia y de provisión de recursos judiciales efectivo a los derechos económicos, sociales y culturales, en el mismo sentido en el que la comunidad internacional lo ha hecho respecto del reconocimiento de estos derechos en un pacto internacional (COURTIS, s.d, inédito II).

Com a adoção do protocolo facultativo, se teve uma atenção voltada para os direitos sociais, principalmente na esfera judicial. Langford (2009) destaca em seu estudo sobre a seara judicial e jurisprudencial dos direitos sociais que a maior parte dos casos de grande impacto e dos casos que motivaram o estabelecimento de novos precedentes jurisprudenciais em relação a estes direitos, foram apresentados por movimentos sociais, comunidades indígenas, organizações de direitos humanos e de mulheres, bem como grupos que trabalham pelos direitos de crianças, migrantes, minorias, pessoas com deficiência e pessoas que vivem com HIV/AIDS, com um grau considerável de coordenação e suporte. Estes novos atores não-estatais somam-se ao movimento sindical tradicional e, em geral, estão mais dispostos a utilizar os tribunais como instrumentos de mudança social.

Até mesmo nos mecanismos processuais é notório a não preocupação com a tutela dos direitos sociais. Abramovich e Courtis (2005) salientam a inadequação dos mecanismos processuais para a proteção dos direitos sociais, os autores afirmam que a maioria das ações judiciais foram feitas e pensadas para a proteção dos direitos civis clássicos, não tendo os direitos sociais ações judiciais específicas para melhor exigi-los judicialmente, principalmente porque os primeiros possuem um amparo individual e não coletivo, como demanda a categoria dos direitos sociais.

Além disso, é preciso considerar que a concretização dos direitos sociais, por demandar vultosos gastos públicos, depende de decisões complexas, que o raciocínio jurídico-formal e adentram na ciência das finanças, na gestão pública e, sobretudo, na política (ALARCON, 201). Os direitos sociais, ao contrário dos direitos civis e políticos, são considerados de alto custo, por isso a temática reserva do possível ${ }^{9}$ e efetivação dos direitos sociais é tão indissociável. Os direitos individuais em contrapartida, são tidos como direitos

\footnotetext{
${ }^{9}$ A expressão surgiu na Alemanha, em 1972, fruto de uma ação judicial impetrada por alunos que pleiteavam ingressar no curso de medicina em uma universidade pública. A alegação foi de que a lei fundamental da Alemanha garantia o direito à formação profissional. Na justificativa, os autores, realizando uma interpretação sistemática da norma, enfatizaram que a limitação no número de vagas ofertadas, violaria tal preceito. Em contrapartida, o Tribunal Constitucional utilizou o argumento de que este limite fático (de vagas) era equivalente a capacidade financeira do Estado e isto estaria dentro do limite da reserva do possível.
} 
negativos que impõem deveres de abstenção ao Estado, logo, para parte da doutrina não demandam um dispêndio financeiro tão alto se comparado aos direitos sociais.

Em específico no sistema interamericano de direitos humanos, chama-se atenção para o fato de que não há um órgão de tutela ou que fiscalize a proteção dos direitos sociais:

O Sistema Interamericano simplesmente invoca um parâmetro de ação para o Estado, legitimando o encaminhamento de comunicações de indivíduos e entidades não governamentais se tais parâmetros (direitos previstos na Convenção e Protocolos) forem desrespeitados. Com isso, essa se torna a sistemática internacional regional de proteção, supervisão e monitoramento do modo pelo qual os Estados garantem os direitos humanos fundamentais (SOUZA, 2014, p.50).

Os direitos sociais nasceram vinculados a direitos de prestação, que exigem uma ação positiva por parte do Estado. A partir disso, a teoria dos direitos sociais encontra outro obstáculo para a sua concretização, a denominada reserva do possível. Como pondera Olsen:

A reserva do possível surge como um excelente escudo para a ineficácia dos direitos fundamentais a prestações positivas, como os direitos sociais, pois nada poderia ser feito - ainda que houvesse "vontade política" - face à escassez de recursos. Interessante que estes recursos nunca são escassos para outros fins, de modo que a própria noção de escassez merece ser investigada, e não tomada como um dado de verdade irrefutável (OLSEN, 2012, p.125).

Quando se atribui que somente os direitos sociais são destinados por obrigações positivas, é necessário para isso verificar o aporte financeiro disponível para concretizá-los. A moradia é tida como um direito social de alto custo, de difícil implementação. O orçamento destinado a programas habitacionais ainda é reduzido se comparado a tutela de outros direitos sociais como a saúde e a educação.

Conforme já discorrido, os direitos, tanto individuais como sociais, visam proteger os indivíduos, suas necessidades e interesses vitais. A moradia é um exemplo disso.

A moradia digna e adequada é fundamental para que um ser humano possa ter uma vida decente, em paz e com segurança. Porém, não basta ter um lar, a moradia é um direito complexo, que acarreta em assegurar outros direitos fundamentais (PRUJEL, 2010). Como os demais direitos sociais, a moradia carece de efetividade e encontra desafios também em sua exigibilidade.

Parcela considerável dos direitos sociais foram estabelecidos por meio de normas programáticas, que de acordo com a doutrina tradicional, atribui como meramente diretiva ao legislador infraconstitucional, mas que não constitui um direito diretamente aplicável. Assim, 
os direitos sociais não seriam direitos subjetivos capazes de definir consequências jurídicas ao Estado em caso de descumprimento.

Em vista dos argumentos apresentados, não pairam dúvidas de que o acesso à moradia é necessário para a manutenção da vida humana. A Constituição brasileira reconhece o direito de moradia como um direito fundamental, porém, a este direito esbarra no desafio da justiciabilidade quando a questão é levada ao poder judiciário: direito de alto custo e com escassa possibilidade de tornar-se uma pretensão jurídica.

\section{Considerações Finais}

A Constituição é a ordem jurídica de um Estado, assume nuances não só de esquematizar a organização do poder estatal bem como definir fins e objetivos para a sociedade e o Estado. O constitucionalismo atual adequou-se a teoria da constituição dirigente proposta por J.J. Gomes Canotilho que através de sua tese de doutoramento, atribuí que por meio das chamadas normas programáticas que possuem conteúdo econômico- social e função de programa, estabelecendo diretrizes para os órgãos públicos.

Os intitulados direitos sociais por vezes são estabelecidos por estas normas, através de regras que estabelecem um direito a uma prestação do Estado, a uma ação de futura concretização. A moradia, enquanto direito social, é um exemplo disso.

A falta de acesso à moradia atinge principalmente países periféricos e que carecem de políticas públicas. Quando analisado no contexto constitucional brasileiro, a moradia está prevista de forma expressa e no rol dos direitos sociais-fundamentais. Apesar dos avanços no plano jurídico- formal, o direito de ter um domicílio, o acesso a este direito, esbarra no obstáculo da justiciabilidade por ainda não ser configurado como um direito subjetivo.

Como já discorrido, a moradia é um direito complexo, envolve outros direitos para sua plena eficácia. A Constituição da República de 1988 salvaguarda o direito à moradia, porém com uma vasta deficiência normativa que colabora para sua indeterminação. Cabe ressaltar, que o direito à moradia não deixa de ser um direito fundamental ocorre que, não existem garantias processuais e substantivas para resguardá-lo.

Parte desta indeterminação se dá pelas distorções da tese estrutural em relação aos próprios direitos sociais. Se comparados aos direitos civis e políticos, os direitos sociais são considerados mais vagos, indeterminados, de alto custo porque demandariam uma atuação 
positiva do Estado e sua realização condicionada às possibilidades fáticas e econômicas. Os direitos civis e políticos ao contrário, são atribuídos como não onerosos, negativos e de fácil proteção pelo poder estatal.

A vagueza dos direitos sociais não os determina como direitos subjetivos. $\mathrm{O}$ acesso à moradia quando analisado na Constituição brasileira de 1988 não preconiza quem tem possibilidade de solicitar este direito, de que maneira, se está tutelando um direito coletivo ou individual. Não está suficientemente claro nem qual conduta que se obriga ao assegurar o direito, nem quem são os sujeitos obrigados.

A atribuição de baixa efetividade das normas programáticas também é outro fator que colabora para a pouca exigibilidade do direito à moradia digna. Parte da doutrina tradicional assevera que estes comandos não obrigam diretamente o poder público, negando aplicabilidade às mesmas. É necessário atentar-se de que estas normas são sim dotadas e eficácia normativa, seguramente. $O$ adjetivo não desqualifica o substantivo a que vem acoplada (MIRANDA, 2003).

A presente pesquisa concluiu que se carece de políticas públicas habitacionais, principalmente porque a progressividade é um dos pilares a ser observado pelo Estado de acordo com o Pacto Internacional dos Direitos Econômicos, Sociais e Culturais (PIDESC). Ademais, a moradia é um dos direitos sociais que ainda depende de uma proteção mais abrangente em termos de exigibilidade, sendo necessários instrumentos jurídicos e estratégias para a defesa e promoção deste direito. Por conseguinte, o direito à habitação não poder ficar determinado no âmbito das opções constitucionais e políticas, é necessário a concretização de seu conteúdo pelo legislador ordinário através de uma verdadeira política de Estado.

\section{Referências}

AINA, Eliane Maria Barreiros. O fiador e o direito à moradia: Direito fundamental à moradia frente à situação do fiador proprietário de bem de família. Rio de Janeiro: Lumen Juris, 2004.

ABRAMOVICH, Victor; COURTIS, Christian. Apuntes sobre la exigibilidad judicial de los derechos sociales. Jura gentium: Rivista di filosofia del diritto internazionale e dela politica globale, $\quad 2005 . \quad$ Firenze, Disponível em: <http://www.juragentium.org/topics/latina/es/courtis.htm>. Acesso em: 30. Jan. 2019. 
ABRAMOVICH, V; COURTIS. Direitos sociais são exigíveis. Dom Quixote: Porto Alegre, 2011.

ALARCON, Sylvio . O Poder Judiciário e as políticas públicas: algumas questões sobre a justiciabilidade dos direitos sociais. In: $1^{\circ}$ Encontro dos Grupos de Pesquisa do Departamento de Direito Privado da Universidade Estadual Paulista (UNESP), 2010, Franca. Caderno de Pesquisas. Franca: UNESP-FHDSS, 2010. v. 1. p. 87-92.

BARROSO, Luís Roberto. Neoconstitucionalismo e constitucionalização do direito? O triunfo tardio do direito constitucional no Brasil. Disponível em <http://bibliotecadigital.fgv.br/ojs/index.php/rda/article/view/43618>. Acesso em: novembro de 2018.

BELlOCHIO, Lúcia; CORVALÁN, Juan Gustavo. O estado atual da jurisprudência argentina sobre direito à moradia. Rev. Direito Administrativo \& Constitucional, ano 14, n 57, p.71-83, jul./set. 2014, Belo Horizonte.

CANOTILHO, José Joaquim Gomes. Constituição Dirigente e Vinculação do Legislador: Contributo para a Compreensão das Normas Constitucionais Programáticas, $2^{\mathrm{a}}$ ed, Coimbra, Coimbra Ed., 2001.

COMANDUCCI, Paolo. Formas de (Neo)Constitucionalismo: un análisis metateórico. ISONOMÍA Revista de Teoría y Filosofía del Derecho. n. 16, abr. 2002.

COURTIS, C. El aporte de los sistemas internacionales de derechos humanos a la justiciabilidad de los derechos económicos, sociales y culturales. Oficina del Alto Comisionado de Naciones Unidas para los Derechos Humanos. Ginebra. s.d., inédito.II

GARGARELLA, Roberto; PÁDUA, Thiago; GUEDES, Jefferson. Constitucionalismo latino- americano: direitos sociais e a "sala de máquinas" da Constituição. In: Universitas JUS, v. 27, n. 2, p. 33-41, 2016.

GENEVOIS, Marie Louise Bulhões Pedreira; COSTA, Olavo Viana. Carência habitacional e déficit de moradias: questões metodológicas. São Paulo Perspec., São Paulo, v. 15, n. 1, p. 73-84, Jan. $2001 \quad$. Available from http://www.scielo.br/scielo.php?script=sci_arttext\&pid=S0102-

$\underline{88392001000100009 \& \operatorname{lng}=\mathrm{en} \& \mathrm{nrm}=\mathrm{iso}}$. Acesso em novembro de 2018. 
HABERMAS, Jürgen. Más allá del Estado Nacional. Madrid: Trotta, 1998.

MENDES, Gilmar Ferreira. Direitos fundamentais e controle de constitucionalidade. 2 ed. São Paulo: Celso Bastos Editor: Instituto Brasileiro de Direito Constitucional, 1999.

MIRANDA COUTINHO, Jacinto Nelson de. (Org.). Canotilho e a constituição dirigente. Rio de Janeiro: Renovar, 2003.

MOLINARO, Carlos Alberto; MEDEIROS, Fernanda Luiza Fontoura de; SARLET, Ingo Wolfgang; FENSTERSEIFER, Tiago (Org.). A dignidade da vida e os direitos fundamentais para além dos humanos: uma discussão necessária. p.175-205.Belo Horizonte: Fórum, 2008.

LOPES, Roberta Castilho Andrade. A construção do direito à moradia no Brasil: da formação da norma à judicialização no Tribunal de Justiça do Estado de São Paulo. Dissertação (Dissertação em Arquitetura e Urbanismo) - Universidade de São Paulo. São Paulo, 2014.

OLSEN. Ana Carolina Lopes. Direitos fundamentais sociais: efetividade frente à reserva do possível. Curitiba: Juruá, 2012.

PECES- BARBA, Gregorio. La constitución y los derechos. Bogotá: Universidad Externado de Colombia, 2006.

PRUJEL, Elodia Almirón. El derecho a una vivienda adecuada: notas para su exigibilidad. Revista Jurídica Universidad Americana. Vol.1, 2010, p. 13-36.

SARLET. I. O Direito fundamental a moradia na constituição: algumas anotações a respeito de seu contexto, conteúdo e possível eficácia. In: Revista Eletrônica sobre a Reforma do Estado ${ }^{\circ}$ 20, 2010.

SERRANO JÚNIOR, Odoné. O direito humano fundamental à moradia digna: exigibilidade, universalização e políticas públicas para o desenvolvimento. Curitiba: Juruá Editora, 2012.

SILVA, José Afonso da. Aplicabilidade das normas constitucionais. 3. ed. São Paulo: Malheiros, 1998.

VALLE, Vanice Regina Lírio do; GOUVÊA, Carina Barbosa. Direito à moradia no Brasil e na Colômbia: uma perspectiva comparativa em favor de um construtivismo judicial. In: 
XXIII Encontro Nacional do CONPEDI, 2014, Florianópolis. Direitos sociais e políticas públicas I:XXIII Encontro Nacional do CONPEDI. Florianópolis: CONPEDI, 2014, pg. 219-245.

WOLKMER, Antonio Carlos. PETTERS MELO, Milena. Constitucionalismo LatinoAmericano: Tendências Contemporâneas. Curitiba: Juruá, 2013. 